\title{
The Role of Oxidized Carbides on Thermal- Mechanical Performance of Polycrystalline Superalloys
}

\author{
PARASKEVAS KONTIS, ZHUANGMING LI, MIKAEL SEGERSÄLL, \\ JOHAN J. MOVERARE, ROGER C. REED, DIERK RAABE, and BAPTISTE GAULT
}

\begin{abstract}
Oxidized MC carbides which act as main crack initiation sites in a polycrystalline superalloy under thermal-mechanical fatigue (TMF) conditions at $850{ }^{\circ} \mathrm{C}$ were studied. Microstructural observations in the TMF tested specimens were compared to findings from bulk samples exposed isothermally in air at $850{ }^{\circ} \mathrm{C}$ for 30 hours in the absence of any external applied load. Carbides were found to oxidize rapidly after exposure at $850{ }^{\circ} \mathrm{C}$ for 30 hours resulting in surface eruptions corresponding to oxidation products, from where micro-cracks initiated. Plastic deformation due to volume expansion of the often porous oxidized carbides led to high dislocation densities in the adjacent matrix as revealed by controlled electron channeling contrast imaging. The high dislocation density facilitated the dissolution kinetics of $\gamma^{\prime}$ precipitates by segregation and diffusion of chromium and cobalt along the dislocations via pipe diffusion, resulting in the formation of soft recrystallized grains. Atom probe tomography revealed substantial compositional differences between the recrystallized grains and the adjacent undeformed $\gamma$ matrix. Similar observations were made for the TMF tested alloy. Our observations provide new insights into the true detrimental role of oxidized MC carbides on the crack initiation performance of polycrystalline superalloys under TMF.
\end{abstract}

https://doi.org/10.1007/s11661-018-4709-x

(C) The Author(s) 2018

\section{INTRODUCTION}

THE thermal-mechanical fatigue (TMF) performance of nickel-based superalloys is a critical parameter in designing new superalloys with superior lifetime and performance. ${ }^{[1]}$ Superalloys subjected to non-isothermal conditions, akin to actual service conditions, provide more representative insights into crack initiation sites and deformation mechanisms as compared to isothermal tests. ${ }^{[2]}$ In particular, in the case of single-crystal superalloys, fracture along deformation twins and bands of sheared $\gamma^{\prime}$ precipitates, which are the main deformation mechanisms, has been reported. ${ }^{[3,4]}$ In addition, deformation twins and grain boundaries were found to act as crack initiation sites in polycrystalline

PARASKEVAS KONTIS, ZHUANGMING LI, DIERK RAABE, and BAPTISTE GAULT are with the Max-Planck-Institut für Eisenforschung, Max-Planck-Str. 1, 40237 Düsseldorf, Germany. Contact e-mail: p.kontis@mpie.de MIKAEL SEGERSÄLL and JOHAN J. MOVERARE are with the Engineering Materials, Department of Management and Engineering, Linköping University, 58183 Linköping, Sweden. ROGER C. REED is with the Department of Materials, University of Oxford, Parks Road, Oxford OX1 3PH, UK.

Manuscript submitted March 1, 2018.

Article published online May 31, 2018 superalloys. ${ }^{[5-7]}$ Nevertheless, there is a growing body of evidence that oxidized MC carbides and the associated recrystallization serve as the main crack initiation sites in polycrystalline superalloys, substantially deteriorating their crack initiation performance. ${ }^{[8-12]}$ However, it is not clear how cracks initiate from carbides and to what extent these are more detrimental to the crack initiation life of polycrystalline superalloys in comparison to deformation twins.

In this study, out-of-phase thermal-mechanical fatigue (OP-TMF) tests were performed on the polycrystalline variant of the recently developed nickel-based superalloy STAL15-CC.$^{[13,14]}$ Scanning electron microscopy (SEM) and controlled electron channeling contrast imaging (cECCI) were used to characterize the deformed microstructure. Atom probe tomography (APT) was utilized to study the composition of the recrystallized regions around the oxidized MC carbides. APT revealed segregation of solutes to dislocations during deformation at $850^{\circ} \mathrm{C}$. Near-atomic scale characterization of solute segregation to dislocations by APT allows us to provide new insights into the diffusion of solutes such as chromium and cobalt along dislocations via pipe diffusion, which leads to local chemical inhomogeneities, facilitating dissolution of $\gamma^{\prime}$ precipitates and the subsequent recrystallization in the vicinity of 
oxidized MC carbides, promoting crack propagation. These observations shed light onto the crack initiation mechanism.

\section{EXPERIMENTAL PROCEDURES}

\section{A. Materials and Mechanical Testing}

The polycrystalline version of the recently developed STAL15-CC was used in this study with chemical composition Ni-16.50Cr-5.50Co-0.60Mo-1.20W-10.00Al$2.40 \mathrm{Ta}-0.5 \mathrm{C}-0.08 \mathrm{~B}$ (at. pct). After conventional casting, a hot isostatic press (HIP) at $1195^{\circ} \mathrm{C}$ for 5 hours under $175 \mathrm{MPa}$ pressure was performed. The process of HIP was followed by a stage of primary aging at $1120^{\circ} \mathrm{C}$ for 4 hours and a subsequent second stage of aging at $845^{\circ} \mathrm{C}$ for 24 hours, both followed by air cooling. TMF specimens with an approximate diameter of $6.35 \mathrm{~mm}$ and a parallel length of $25 \mathrm{~mm}$ were machined from fully heat-treated cast bars, with surface finish Ra $0.2 \mu \mathrm{m}$. All TMF tests were performed using an Instron servohydraulic TMF machine equipped with induction heating and a forced air cooling system. In order to accurately control the temperature of the specimens, thermocouples were carefully spot-welded on the specimens. The OP-TMF tests were conducted under strain control in the temperature range $100{ }^{\circ} \mathrm{C}$ to $850{ }^{\circ} \mathrm{C}$ at $R_{\varepsilon}=-\infty$. A heating rate of $5{ }^{\circ} \mathrm{C} / \mathrm{s}$ was selected with a 5 -minute dwell time applied at maximum temperature during each cycle. Finally, for the control of the strain range, a high-temperature extensometer with a gauge length of $12.5 \mathrm{~mm}$ was used.

\section{B. Microstructural Characterization}

The surface and the cross section of the TMF tested specimens were observed using a Zeiss Merlin (Carl Zeiss SMT AG, Germany) scanning electron microscope (SEM). The cross-section surfaces were mechanically ground with abrasive media to $0.04 \mu \mathrm{m}$ finish. The observations from the TMF tested specimens were compared with microstructural features from flat polished specimens of STAL15-CC with $1 \mu \mathrm{m}$ surface finish, which were isothermally and statically exposed in air at $850{ }^{\circ} \mathrm{C}$ for 30 hours. The cross section of these specimens was imaged by using cECCI on a Zeiss Merlin SEM with a Gemini-type field emission gun electron column and a Bruker e-FlashHR EBSD detector (Bruker Corporation, USA).

For the observation of dislocations within the deformed microstructure, ECCI under controlled diffraction conditions was utilized following the procedures described in Reference 15. Selection of the optimal diffraction conditions in terms of rotation and tilt angles was made by simulated electron channeling patterns based on a preceding EBSD analysis in the region of interest and by use of the software TOCA. ${ }^{[15]}$ The microscope was operated at $30 \mathrm{kV}$ accelerating voltage and $3 \mathrm{nA}$ probe current. The specimen was positioned at $7 \mathrm{~mm}$ working distance and was tilted to an angle in the range [ $-4 \mathrm{deg}, 20 \mathrm{deg}]$.
In addition, energy dispersive X-ray (EDX) analysis of the oxidized MC carbides was performed at flat polished (surface finish $0.04 \mu \mathrm{m}$ ) cross section of the statically exposed specimens using a Zeiss $1540 \mathrm{XB}$ SEM, operated at $7 \mathrm{kV}$. Finally, specimens for APT were prepared from both the statically exposed and mechanically tested specimens of STAL15-CC, respectively, following procedures described in detail in Reference 16. Specimens were analyzed on a Cameca LEAP 5000 XR operated in laser mode with a pulse repetition rate of $125 \mathrm{kHz}$, laser pulse energy $50 \mathrm{pJ}$, and at a base temperature of $50 \mathrm{~K}$. The APT reconstructions were performed using the IVAS 3.6.14 software from Cameca.

\section{RESULTS AND DISCUSSION}

\section{A. Crack Initiation Under Thermal-Mechanical Fatigue Conditions}

For the polycrystalline nickel-based STAL15-CC superalloy, cracks initiate from surface-connected oxidized MC carbides when tested under OP-TMF conditions in the temperature range $100{ }^{\circ} \mathrm{C}$ to $850{ }^{\circ} \mathrm{C}$. This is revealed in Figures 1(a) and (b) where surface eruptions of oxides due to the oxidation of the carbides and subsequent cracks can be seen. Both inter- and intragranular carbides oxidize as long as they are connected to the surface. Figure 1(c) shows a backscattered electron micrograph from the cross section of one of the mechanically tested STAL15-CC specimens. The surface eruption of oxides due to the oxidation of the MC carbide is here again clearly shown within the bulk at the fracture surface of the specimen, confirming the observations made on the surface of the specimen. It is worth mentioning that grain boundaries were not found to be cracked as it would be expected for a polycrystalline alloy. By contrast, in most of the cases, cracks initiated within the grains where MC carbides have oxidized. Also, a recrystallized region next to the oxidized $\mathrm{MC}$ carbide and along the fracture surface is observed, Figure 1(d). Although the recrystallization along the fracture surface is believed to be due to the oxidation and the associated volume mismatch leading apparently to local plasticity as the crack propagates, the extensive recrystallization in the vicinity of the oxidized carbide is not well understood and thus our investigations were focused on the rationalization of this microstructural observation.

\section{B. Oxidized MC Carbides}

MC carbides in the STAL15-CC alloy after the full heat treatment process were found to be Ta-rich, whereas other elements such as $\mathrm{Hf}$ and $\mathrm{Zr}$ also participate but in significantly lower amounts. In Figure 2, an APT reconstruction containing an MC carbide and a $\gamma^{\prime}$ precipitate is shown, alongside a proximity histogram, which is an elemental composition profile measured as a function of distance from the $\mathrm{MC} / \gamma^{\prime}$ interface. Table I gives in detail the composition of an MC carbide as 

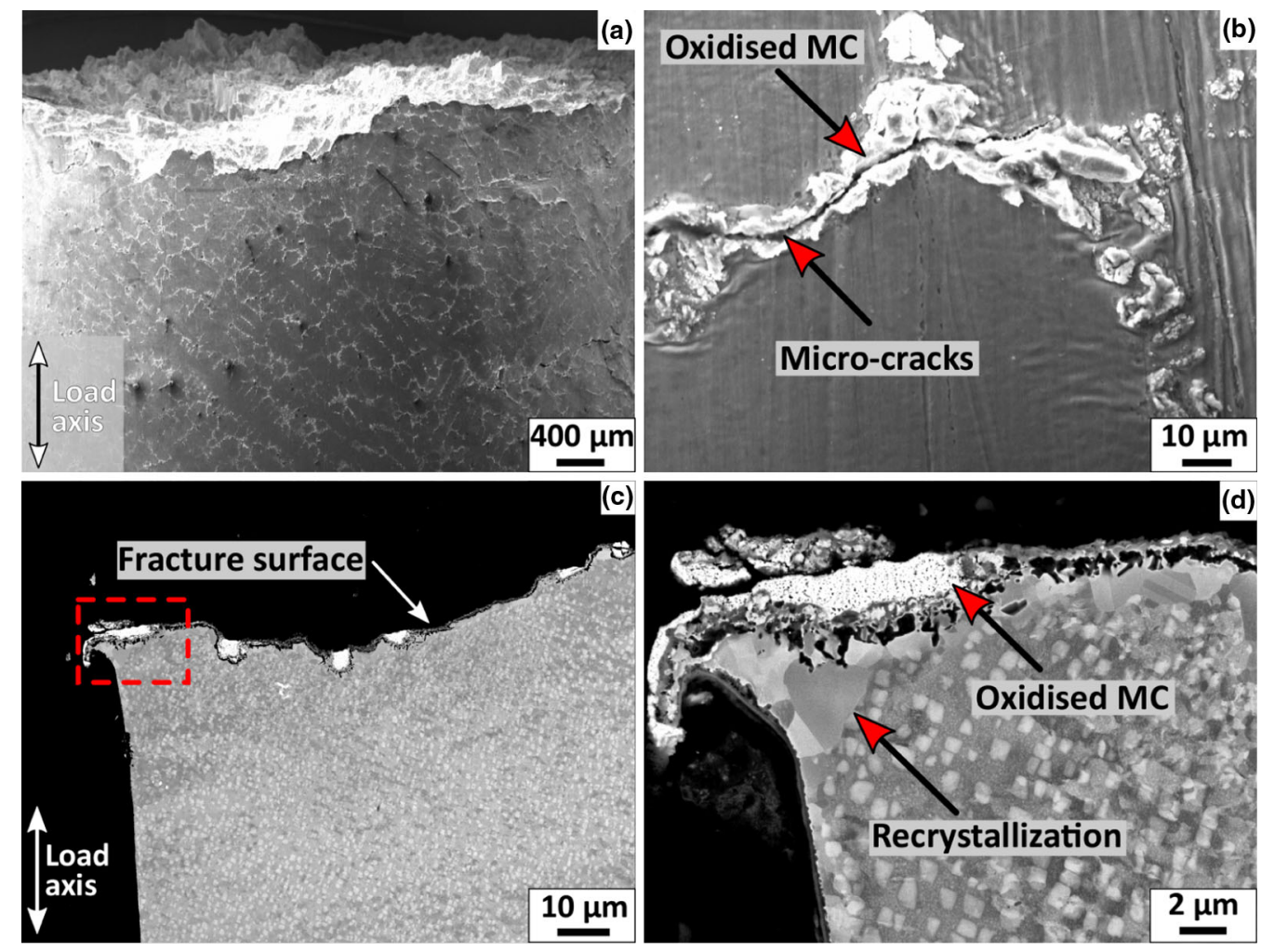

Fig. 1-(a) Secondary SEM micrograph showing oxidized MC carbides on the surface of the STAL15-CC alloy tested under OP-TMF in the temperature range $100{ }^{\circ} \mathrm{C}$ to $850^{\circ} \mathrm{C}$. (b) Secondary SEM micrograph showing micro-cracks initiating at the surface of the OP-TMF specimen from oxidized carbides. $(c)$ Backscatter SEM micrograph of the cross section parallel to load axis showing oxidized MC carbide as the crack initiation site at a OP-TMF specimen. (d) Backscatter SEM micrograph showing the porous oxidized MC carbide and the surface eruption due to oxidation. Recrystallization is also shown next to oxidized carbides and along the fracture surface of the OP-TMF specimen.

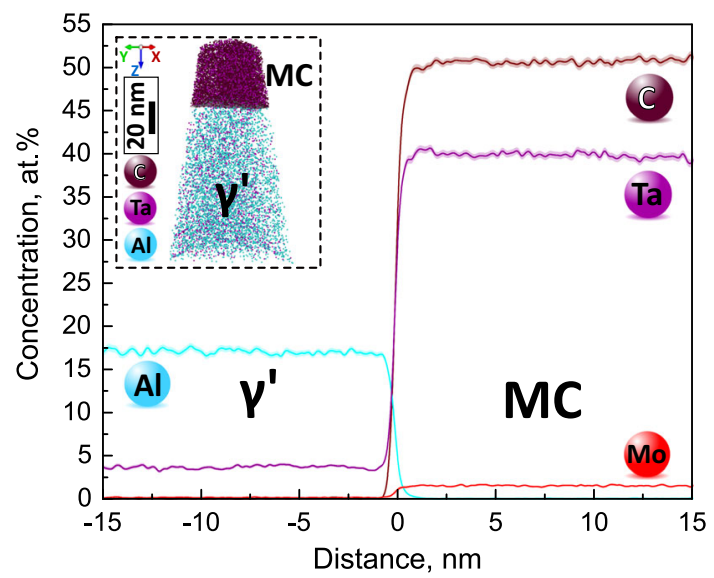

Fig. 2-APT reconstruction from fully heat-treated STAL15-CC alloy containing a Ta-rich MC carbide and a $\gamma^{\prime}$ precipitate, alongside a proximity histogram of their interface. Error bars are shown as lines filled with color and correspond to the $2 \sigma$ counting error.

Table I. Chemical Composition of the MC Carbide After Full Heat Treatment as Measured by Atom Probe Tomography (Atomic Percent)

\begin{tabular}{ccccccccc}
\hline & C & Ta & Cr & Hf & Zr & W & Mo & B \\
\hline MC & 48.4 & 44.0 & 2.0 & 1.7 & 1.2 & 1.0 & 0.9 & 0.2 \\
\hline
\end{tabular}

measured by APT. These observations are in good agreement with a previous APT study on STAL15-CC alloy. ${ }^{[14]}$ The MC carbides precipitating at the grain boundaries exhibit an elongated or blocky morphology with size ranging from 1 to $7 \mu \mathrm{m}$. Intragranular carbides have either a script-like shape or they have an elongated morphology with a size up to approximately $12 \mu \mathrm{m} .{ }^{[14]}$

In order to investigate whether the recrystallization is associated with the oxidation of the carbides or with the external applied load, specimens exposed statically and isothermally in air at $850{ }^{\circ} \mathrm{C}$ for 30 hours were investigated. Figure 3 shows an EDX map from a cross section of the statically exposed specimen, confirming the oxidation of the Ta-rich MC carbides after 30 hours exposed at $850^{\circ} \mathrm{C}$.

Figure 4(a) shows another intragranular oxidized MC carbide where the surface eruption as well as a recrystallized region in the vicinity of the carbide are readily apparent, confirming that recrystallization occurs in the absence of external applied stress. Substantial volume expansion due to the oxidation of MC carbides was shown to result in localized plastic deformation in other polycrystalline superalloys. ${ }^{[17,18]}$ Assuming that the $\mathrm{TaC}$ oxidizes to $\mathrm{Ta}_{2} \mathrm{O}_{5}$, an estimation of the volume expansion is complex, because $\mathrm{Ta}_{2} \mathrm{O}_{5}$ exhibits different crystal structures at different temperatures, some of which are not clearly determined. ${ }^{[19]}$ However, an estimation of the volume expansion of $\mathrm{NbC}$ transforming to $\mathrm{Nb}_{2} \mathrm{O}_{5}$ has 

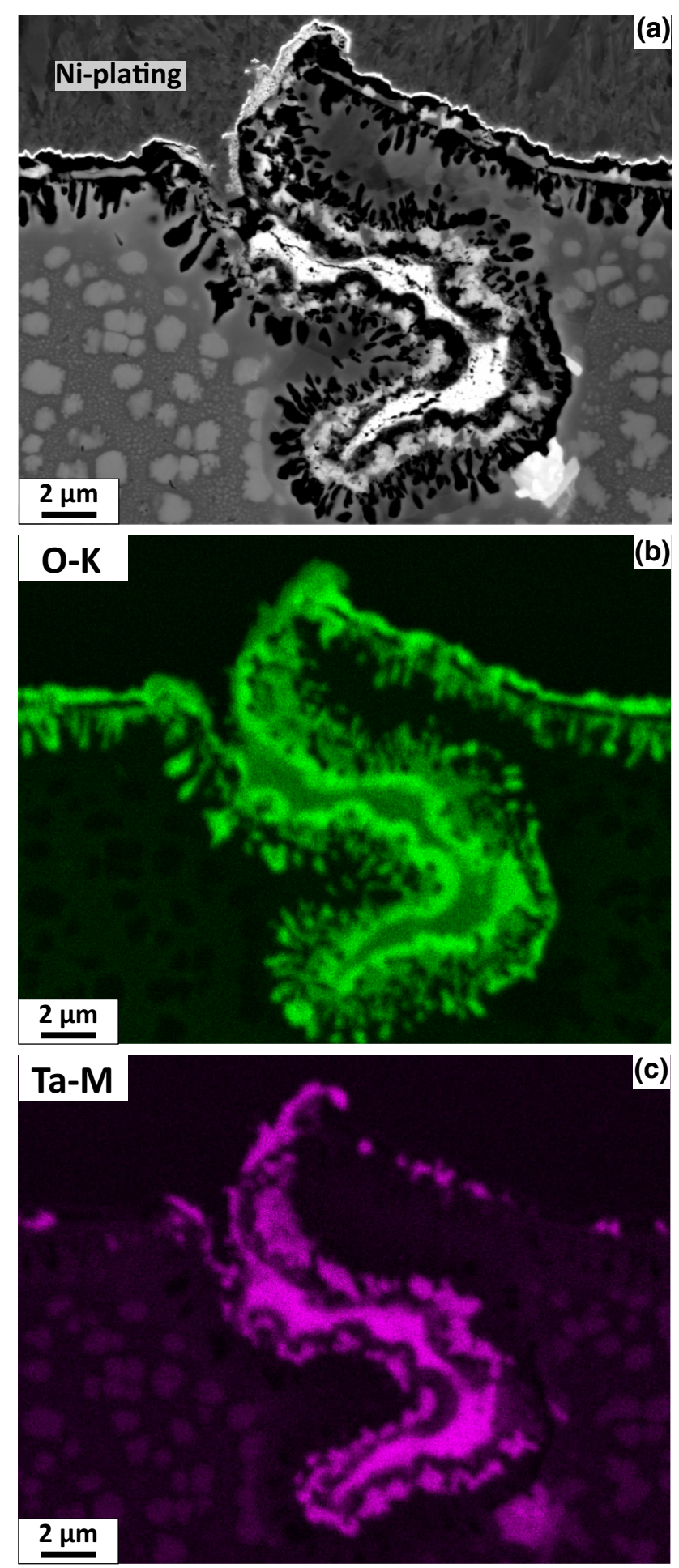

Fig. 3-(a) Backscatter SEM micrograph showing an oxidized MC carbide in the STAL15-CC alloy after static and isothermal exposure at $850{ }^{\circ} \mathrm{C}$ for $30 \mathrm{~h}$, alongside EDX elemental maps of $(b)$ oxygen $(\mathrm{K}$ $\mathrm{X}$-ray emission line) and (c) tantalum (M X-ray emission line).

shown a volume expansion of a factor of two, ${ }^{[17]}$ and expansion factor in the range can likely be expected in the case of $\mathrm{Ta}_{2} \mathrm{O}_{5}$.
The recrystallization likely results only from the plastic deformation due to volume expansion of the carbide as it gets oxidized. This is confirmed by cECCI micrographs which reveal a high dislocation density in the recrystallized regions as shown in Figure 4(b) and also between the recrystallized region and the heattreated microstructure as shown in Figures 4(c) and (d). An ECCI micrograph from the mechanically deformed specimen under OP-TMF shown in Figure 5 exhibits similar microstructural characteristics. However, in this case, the dislocation density within the recrystallized regions is higher, which can be attributed to the externally applied stress. The high dislocation density also explains the accelerated local dissolution of the $\gamma^{\prime}$ precipitates due to pipe diffusion and the Gibbs adsorption of solute elements to the dislocation core regions.

It was observed that a $\gamma^{\prime}$-depleted zone forms below the protective oxide scale at the surface of superalloys after thermal exposure at elevated temperatures. ${ }^{[20]}$ However, in the case of the short static thermal exposure, recrystallization is more pronounced around the oxidized carbide and not along the entire length of the surface of the specimen. This observation suggests that the dissolution of $\gamma^{\prime}$ precipitates and the subsequent recrystallization are not products of the oxide scale formation, but instead of a different phenomenon as discussed below in more detail.

\section{Dissolution of $\gamma^{\prime}$ Precipitates}

The dissolution of $\gamma^{\prime}$ precipitates and the subsequent recrystallization cannot be accommodated by bulk diffusion alone at such short exposure time (30 hours). It is often assumed that dissolution kinetics of $\gamma^{\prime}$ precipitates can be enhanced by the presence of dislocations in the microstructure, more specific through pipe diffusion of solutes along dislocations and also through the trapping of solutes to the dislocations. ${ }^{[21-23]}$ APT was utilized for the investigation of segregation of solutes at dislocations in both isothermally exposed and mechanically tested specimens of STAL15-CC.

Specimens for APT were prepared in an area with a high dislocation density in the $\gamma / \gamma^{\prime}$ region next to the oxidized carbide from the sample treated by isothermal static exposure at $850{ }^{\circ} \mathrm{C}$ for 30 hours in Figure 4(d). The resulting reconstruction from such an analysis is illustrated in Figure 6(a). It contains a $\gamma / \gamma^{\prime}$ interface that shows interfacial grooves, which likely result from the accumulation of dislocations. Within $\gamma^{\prime}$, a cylindrical tubular feature is highlighted in terms of an isosurface encompassing regions within the point cloud that are enriched in chromium using a threshold value of 8.6 at. pct $\mathrm{Cr}$. This enrichment is due to segregation of solutes at dislocations, which has been previously reported in APT studies conducted on various materials ${ }^{[24-26]}$ and has been unambiguously confirmed by correlative transmission electron microscopy (TEM) and APT analysis. ${ }^{[27,28]}$ A cylindrical region of interest perpendicular to the dislocation, labeled as arrow \#1 in Figure 6(a), reveals chromium and cobalt enrichment at the dislocation as clearly shown in Figure 6(b). Chromium and 

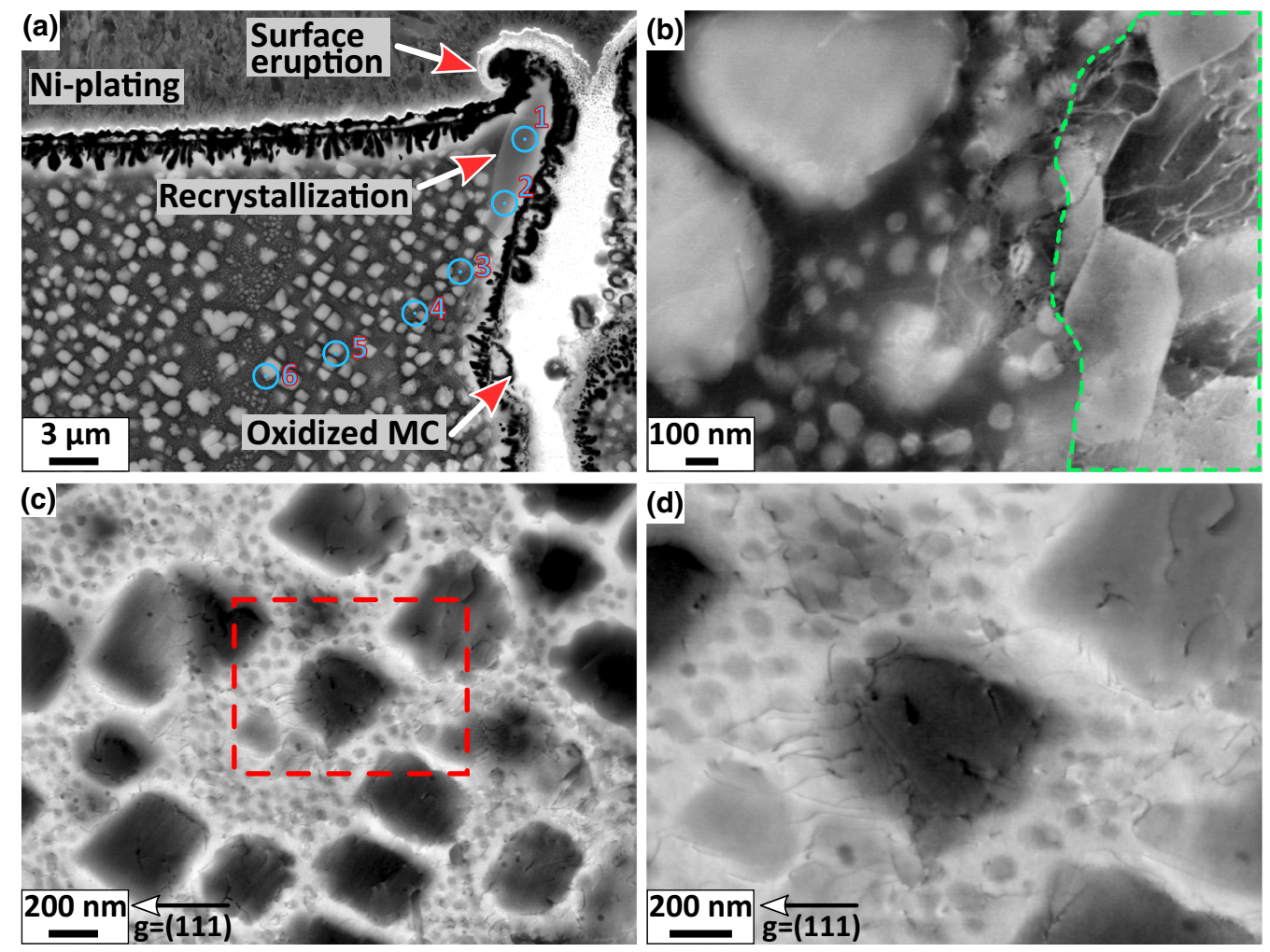

Fig. 4 - (a) Backscatter SEM micrograph showing surface eruption of oxides and recrystallization in the STAL15-CC alloy after static and isothermal exposure at $850^{\circ} \mathrm{C}$ for $30 \mathrm{~h}$. APT specimens were prepared from regions highlighted in blue and the corresponding chemistry is given in Table II. (b) ECCI micrograph showing high dislocation density within the recrystallized region highlighted by the dashed green line. (c) Controlled ECCI micrograph revealing a high dislocation density within the $\gamma / \gamma^{\prime}$ microstructure due to the plastic deformation from the volume expansion from the oxidized MC carbide. (d) Controlled ECCI micrograph from the region denoted by the dashed red box in Fig. 4(c) showing in detail dislocations in the $\gamma / \gamma^{\prime}$ microstructure of STAL15-CC (Color figure online).

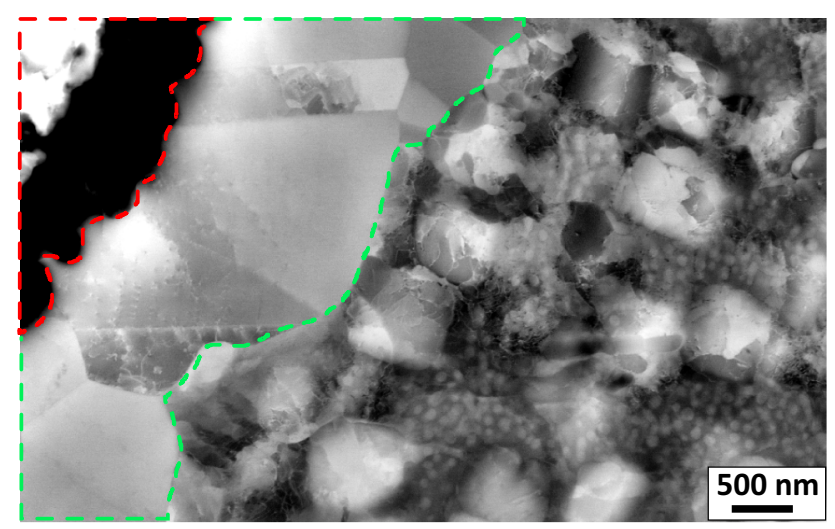

Fig. 5-ECCI micrograph next to an oxidized MC carbide (denoted by the dashed red line) during OP-TMF at $850{ }^{\circ} \mathrm{C}$ showing high dislocation density within the recrystallized region (denoted by the dashed green line) and within the $\gamma / \gamma^{\prime}$ microstructure where dissolution of $\gamma^{\prime}$ precipitates occurs (Color figure online).

cobalt reach enrichment values of approximately 14.0 and 6.0 at. pct, respectively.

Similar observations regarding the segregation and diffusion of chromium and cobalt along dislocations were revealed by APT for two other different nickel-based superalloys. ${ }^{[29]}$ The segregation of chromium and cobalt to dislocations was therein assumed to result in local chemical inhomogeneities and drain these elements from the $\gamma$ matrix. As a consequence, the solubility of nickel in $\gamma$ locally increases, which results in the dissolution of $\gamma^{\prime}$ precipitates.

Similar APT observations were made for the mechanically deformed STAL15-CC under OP-TMF conditions. Figure 7(a) shows an APT reconstruction from the region with a high dislocation density next to the oxidized carbide, shown in Figure 5. Individual dislocations within a $\gamma^{\prime}$ precipitate are made visible by the segregation of chromium and cobalt. Figure 7(b) shows a composition profile computed along a cylindrical region of interest perpendicular to the dislocation, indicated by the arrow labeled \#1 in Figure 7(a), revealing an enrichment in chromium and cobalt of up to 15.0 and 8.0 at. pct, respectively. Aluminum and nickel were found to be depleted at the dislocation. Within the same APT reconstruction, an array of dislocations was also observed as shown in Figure 7(a). The way these dislocations are structured and aligned suggests the formation of a low-angle grain boundary, which could well be the initial step of the development of a new recrystallized grain. It is also interesting that although this array of dislocations exhibits the same segregation character as the ones previously observed in Figure 6 and in other alloys, ${ }^{[29]}$ there is a progressive increase in the level of chromium 


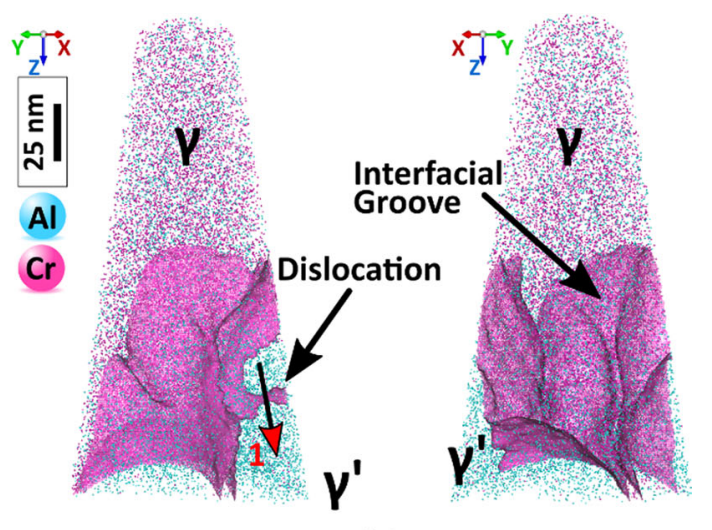

(a)

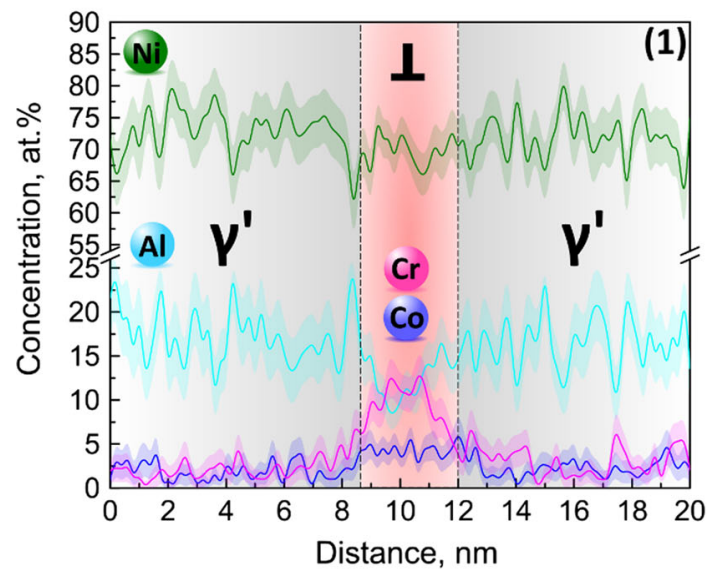

(b)

Fig. 6- (a) APT reconstruction from a high dislocation density $\gamma / \gamma^{\prime}$ region in the vicinity of the oxidized $\mathrm{MC}$ carbide after static oxidation of STAL15-CC, showing a $\gamma / \gamma^{\prime}$ interface, dislocation within the $\gamma^{\prime}$ precipitate, and interfacial grooves. The $\gamma / \gamma^{\prime}$ interface and dislocation are shown with an iso-concentration surface at 8.6 at. pct Cr. (b) 1D concentration profile perpendicular to the dislocation denoted by the arrow \#1 in Fig. 6(a) showing segregation of chromium and cobalt at the dislocation. Error bars are shown as lines filled with color and correspond to the $2 \sigma$ counting error.

segregated from the dislocation labeled \#2 to dislocation labeled \#5 as revealed by the composition profile plotted in Figure 7(c). This trend can be ascribed either to the fact that the segregation and diffusion process are not completed yet or to the different screw or edge character of the dislocations resulting in different segregation and diffusion of solutes. This needs to be further investigated by correlative transmission electron microscopy and APT studies.

\section{Recrystallized $\gamma_{R}$ Grains}

The recrystallized grains which originated from the volume expansion of the oxidized MC carbides exhibit a significantly altered composition compared to the $\gamma$

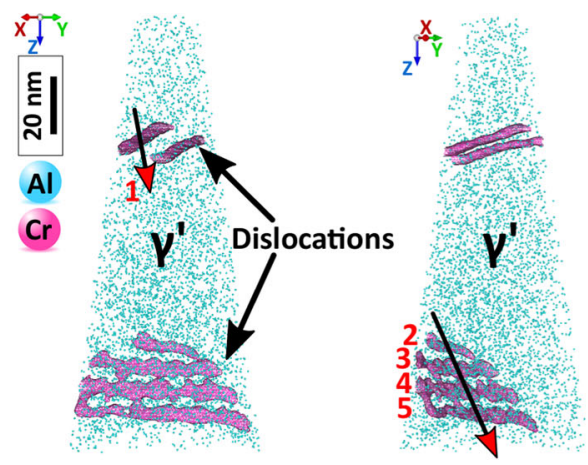

(a)

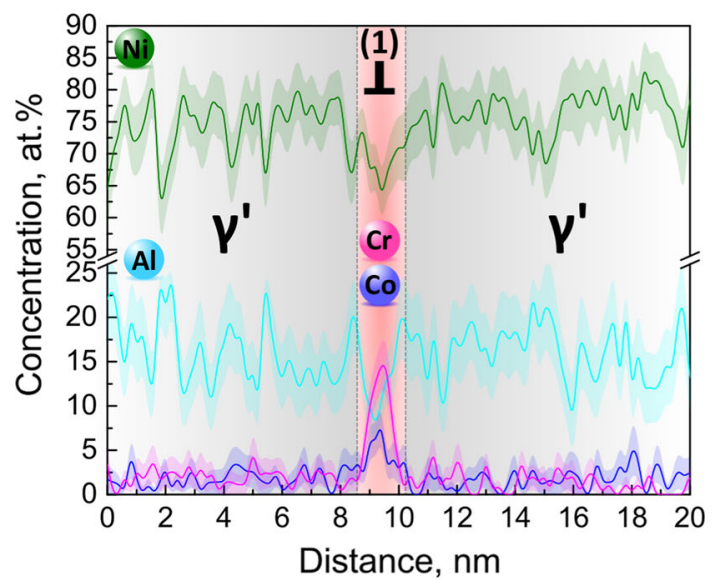

(b)

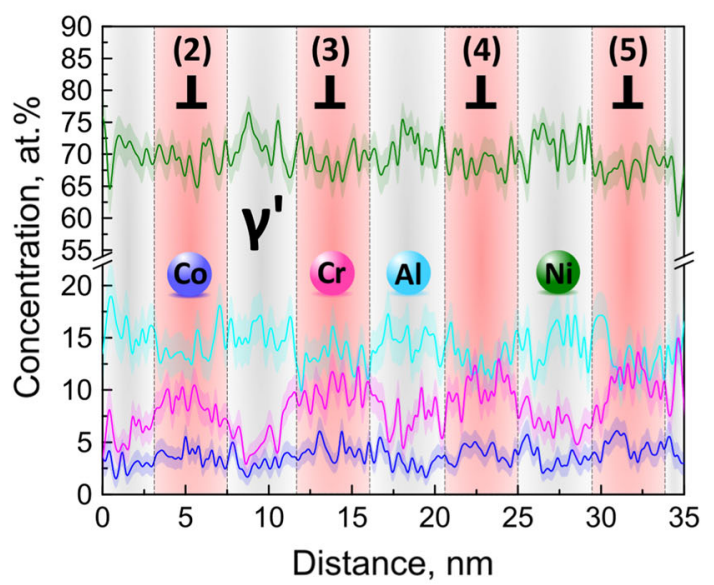

(c)

Fig. 7- (a) APT reconstruction from a high dislocation density $\gamma / \gamma^{\prime}$ region in the vicinity of the oxidized MC carbide after OP-TMF testing at $850{ }^{\circ} \mathrm{C}$ of STAL15-CC, showing dislocations within the $\gamma^{\prime}$ precipitate. The dislocations are shown with an iso-concentration surface at 4.2 at. pct $\mathrm{Cr}$. (b) 1D concentration profile perpendicular to the dislocation denoted by the arrow \#1 in Fig. 7(a) showing segregation of chromium and cobalt at the dislocation. (c) 1D concentration profile perpendicular to the array of dislocations numbered from 2 to 5 in Fig. 7(a). Error bars are shown as lines filled with color and correspond to the $2 \sigma$ counting error. 
matrix. APT analysis was conducted at different locations of the statically exposed STAL15-CC, including positions inside of recrystallized grains, within the adjacent $\gamma$ matrix with its enhanced dislocation density and also in the undeformed $\gamma$ matrix with almost no dislocations present, i.e., far from the deformation zone surrounding the oxidized carbide. The local composition fluctuations from the different regions as highlighted in blue in Figure 4(a) are plotted in Figure 8, progressing from the recrystallized grain into the undeformed $\gamma$ matrix.

In the region of the recrystallized grains, a substantial drop in the chromium content is observed, from 30.9 at. pet in the $\gamma$ matrix to only 12.3 at. pct. The segregation of chromium at dislocations and its diffusion along them is leaching chromium from the matrix and thus rationalizing the low chromium content within the new, recrystallized grains. At the same time, the nickel content increased from 56.5 at. pct in the $\gamma$ matrix to 76.1 at. pet within the recrystallized grains. The APT analysis shows that the composition of the new grains is not corresponding to that of the initial $\gamma$ matrix, thus, as

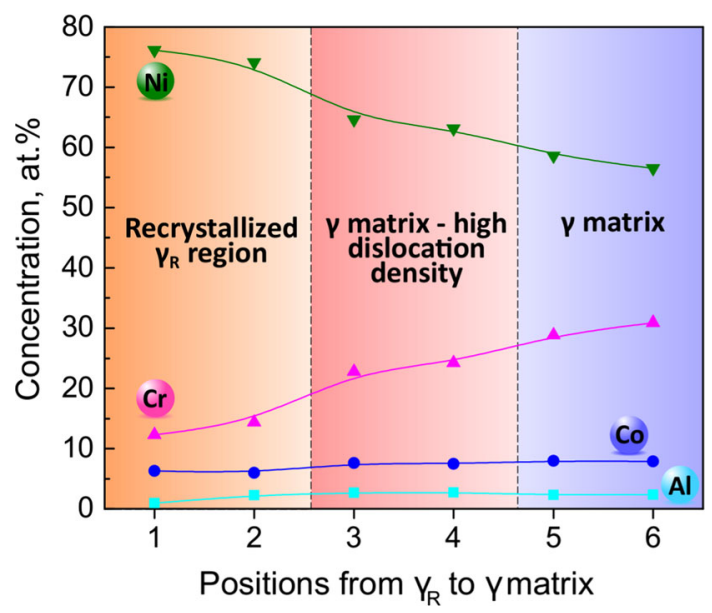

Fig. 8-Graph showing the compositional variations in various positions from the recrystallized $\gamma_{\mathrm{R}}$ grains to $\gamma$ matrix as measured by APT after static and isothermal exposure at $850{ }^{\circ} \mathrm{C}$ for $30 \mathrm{~h}$. proposed in Reference 18, it will be denoted hereafter as $\gamma_{\mathrm{R}}$. Cobalt exhibits a minor decrease from the $\gamma$ matrix towards the $\gamma_{\mathrm{R}}$ region while the aluminum content remains almost constant. Table II lists the detailed compositions as measured by APT for all locations marked in Figure 8. Based on their composition, the recrystallized $\gamma_{\mathrm{R}}$ grains do not contain any strengthening phase and would thus be expected to be softer than the $\gamma$ matrix. This circumstance might explain the high dislocation density observed within them as revealed in Figures 4(b) and 5. Similar observations on the chemistry of $\gamma_{R}$ were found also for a different polycrystalline nickel-based superalloy. ${ }^{[18]}$ However, in that case, both the chromium and the cobalt content were altered substantially and not just chromium as in the case of STAL15-CC. This observation is possibly due to the different bulk composition between the two alloys.

It was mentioned earlier that a pile-up of dislocations, as shown in Figure 7(a), can indicate the nucleation of the new recrystallized $\gamma_{R}$ grains. Figure 9(a) shows an APT reconstruction from a high dislocation density $\gamma / \gamma^{\prime}$ region next to an oxidized carbide from an OP-TMF specimen, containing $\gamma / \gamma^{\prime}$ interfaces, dislocations within a $\gamma^{\prime}$ precipitate, and a thin channel cutting the $\gamma^{\prime}$ precipitate. Figure 9(c) shows the compositional profile along this thin channel, as indicated by arrow \#1 in Figure 9(b). It can be seen that the composition of the channel initially is close to that of $\gamma$ within the high dislocation density region (22.0 at. pet $\mathrm{Cr}$ ), as shown earlier in Figure 8. However, chromium progressively decreases to a content similar to that observed in the $\gamma_{R}$ grains and to that at dislocations (12.0 at. pet $\mathrm{Cr}$ ).

This observation allows proposing a simplified sequence leading to the formation of the $\gamma_{R}$ grains as schematically illustrated in Figure 10. Initially, there is a well-defined interface between the $\gamma^{\prime}$ precipitate and $\gamma$ matrix, before any dislocations approach the $\gamma / \gamma^{\prime}$ interface as shown in Figure 10(a). As more dislocations are generated and start interacting with the $\gamma / \gamma^{\prime}$ interface, grooves at the $\gamma / \gamma^{\prime}$ interface will form (Figure 10(b)). Eventually, as deformation proceeds, dislocations will enter the $\gamma^{\prime}$ precipitate (Figure 10(c)) and a pile-up of dislocations within the $\gamma^{\prime}$ precipitate (Figure 10(d)),

Table II. Summary of Chemical Compositions of the $\gamma_{R}$ Recrystallized Regions, the High Dislocation Density $\gamma$ Matrix, and the $\gamma$ Matrix After Isothermal Exposure in Air at $850^{\circ} \mathrm{C}$ for $30 \mathrm{~h}$ as Measured by Atom Probe Tomography, Corresponding to Graph Shown in Fig. 8 (Atomic Percent)

\begin{tabular}{|c|c|c|c|c|c|c|c|}
\hline & $\mathrm{Ni}$ & $\mathrm{Co}$ & $\mathrm{Cr}$ & $\mathrm{Al}$ & Mo & $\mathrm{W}$ & $\mathrm{Ta}$ \\
\hline$\gamma_{\mathrm{R}}(1)$ & 76.1 & 6.3 & 12.3 & 1.0 & 1.0 & 1.1 & 2.0 \\
\hline$\gamma_{R}(2)$ & 74.1 & 6.0 & 14.3 & 2.3 & 0.8 & 1.0 & 1.4 \\
\hline$\gamma$-high dislocation density (3) & 64.6 & 7.6 & 22.9 & 2.7 & 0.8 & 0.9 & 0.4 \\
\hline$\gamma$-high dislocation density (4) & 63.1 & 7.5 & 24.2 & 2.7 & 1.0 & 0.9 & 0.4 \\
\hline$\gamma$-no dislocation (5) & 58.6 & 8.0 & 28.9 & 2.3 & 1.0 & 0.8 & 0.2 \\
\hline$\gamma$-no dislocation (6) & 56.4 & 7.9 & 31.0 & 2.4 & 1.1 & 0.9 & 0.2 \\
\hline
\end{tabular}



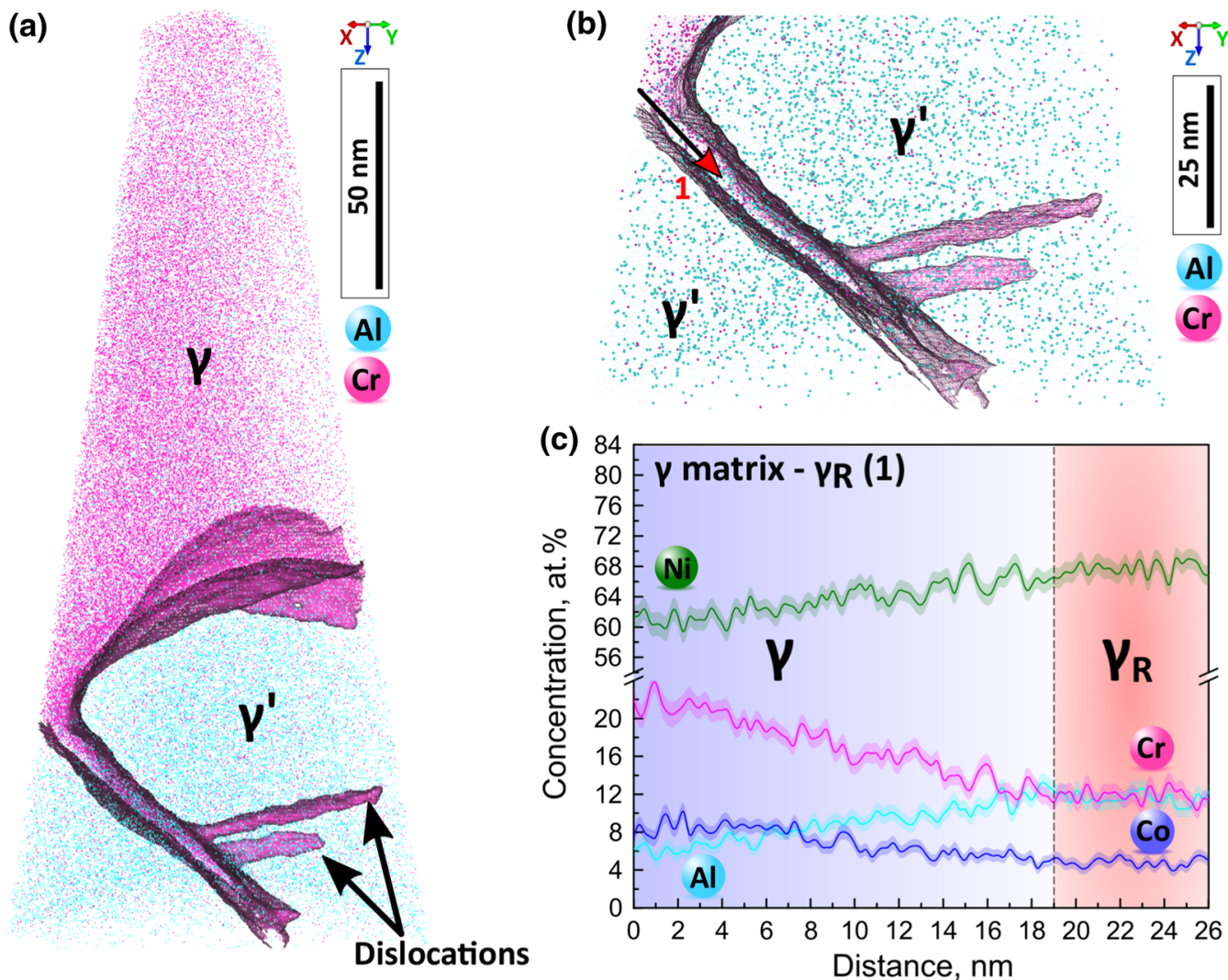

Fig. 9- (a) APT reconstruction from a high dislocation density $\gamma / \gamma^{\prime}$ region in the vicinity of the oxidized MC carbide after OP-TMF testing at $850{ }^{\circ} \mathrm{C}$ of STAL15-CC, showing $\gamma / \gamma^{\prime}$ interfaces, dislocations within the $\gamma^{\prime}$ precipitate, and a thin channel. The $\gamma / \gamma^{\prime}$ interface and dislocations are shown with an iso-concentration surface at 6.0 at. pct Cr. (b) Detail of the atom probe reconstruction from Fig. 9(a) showing the position of the cylindrical region of interest along the channel (arrow \#1). (c) 1D concentration profile along the channel denoted by the arrow \#1 in Fig. 9(b) showing the chemical transition from $\gamma$ matrix to recrystallized $\gamma_{\mathrm{R}}$ region. Error bars are shown as lines filled with color and correspond to the $2 \sigma$ counting error.

similar to the one observed by APT in Figure 7(a), will result either in the nucleation of a $\gamma_{R}$ grain or the formation of a low-angle grain boundary.

\section{SUMMARY}

In summary, we have performed out-of-phase thermal-mechanical fatigue (OP-TMF) tests in a $100{ }^{\circ} \mathrm{C}$ to $850^{\circ} \mathrm{C}$ temperature range in the polycrystalline nickel-based STAL15-CC superalloy. Systematic characterization with cECCI and APT has provided new insights into the crack initiation mechanisms:

- Surface-connected oxidized Ta-rich MC carbides act as main crack initiation sites in the polycrystalline superalloy STAL15-CC. Cracks were not found to initiate at grain boundaries, while their majority cracks initiated within the grains from oxidized MC carbides.
- Plastic deformation due to volume expansion of the oxidized MC carbides results in recrystallization in the vicinity of carbides after static, isothermal exposure loading at $850{ }^{\circ} \mathrm{C}$ for 30 hours. The same microstructural observations were made for the OP-TMF tested specimens, rationalizing the observed crack initiation sites.

- Atom probe tomography reveals segregation of chromium and cobalt at dislocations and their diffusion along dislocations via pipe diffusion. This effect results in local chemical inhomogeneities leading to the dissolution of $\gamma^{\prime}$ and subsequent recrystallization.

- Soft recrystallized $\gamma_{R}$ grains formed with compositions that vary substantially compared to that of the $\gamma$ matrix as revealed by APT analysis. A substantial drop in the chromium content is observed, from 30.9 at. pct in the $\gamma$ matrix to only 12.3 at. pct in the $\gamma_{R}$ grains, whereas the nickel content increased from 56.5 at. pet in the $\gamma$ matrix to 76.1 at. pct in the $\gamma_{R}$ grains. 


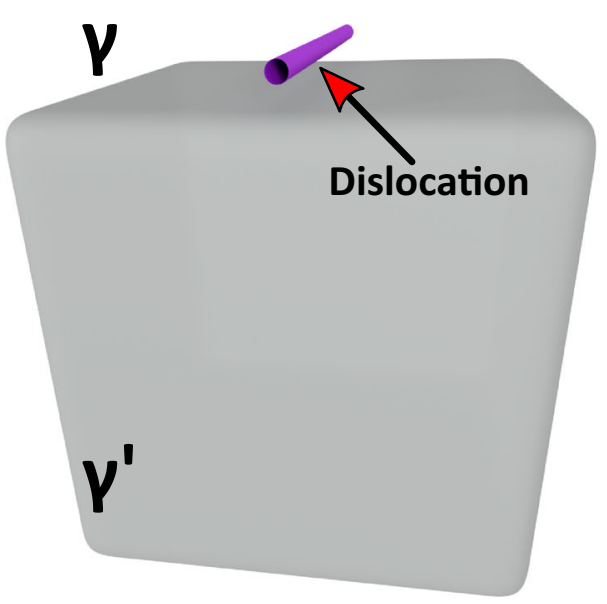

(a)

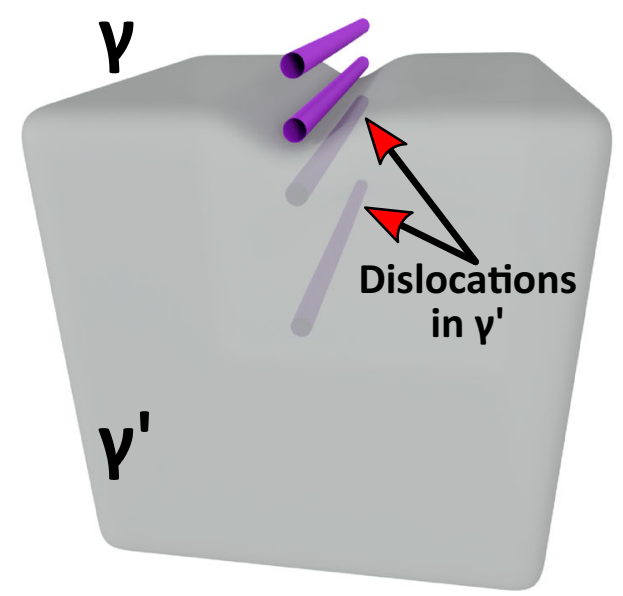

(c)

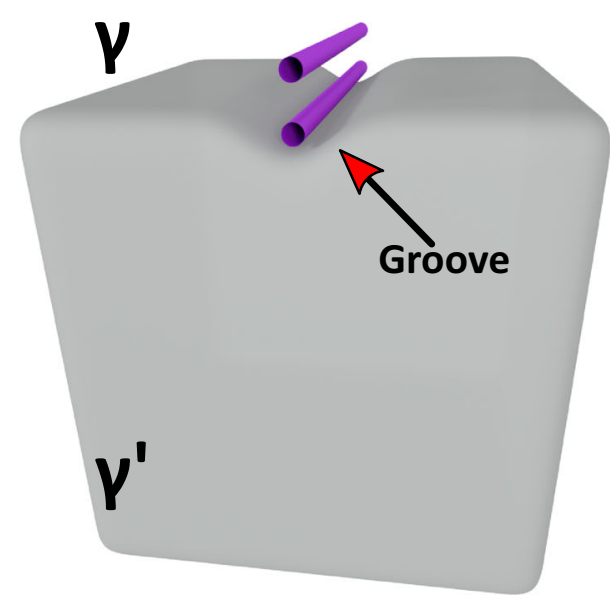

(b)

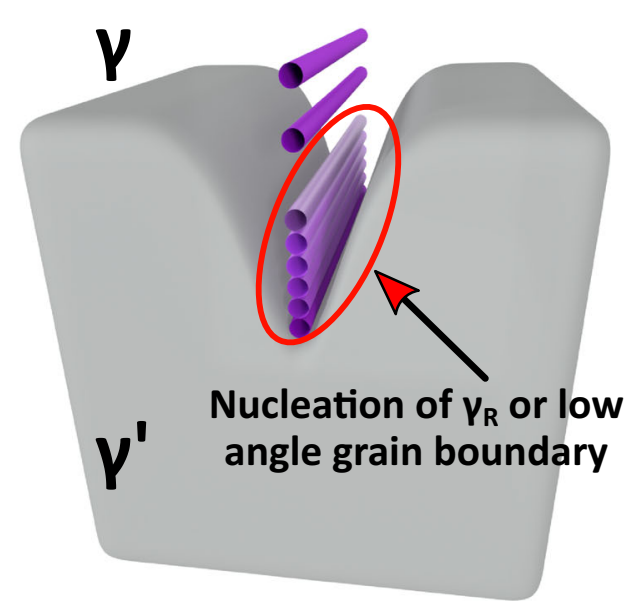

(d)

Fig. 10-Simplified schematic illustration of the nucleation of $\gamma_{\mathrm{R}}$ grains or low-angle grain boundaries. (a) Well-defined $\gamma / \gamma^{\prime}$ interface and dislocation in $\gamma$. (b) Dislocations forming grooves at the $\gamma / \gamma^{\prime}$ interface. (c) Dislocations within the $\gamma^{\prime}$ precipitate $(d)$ Pile-up of dislocations resulting in the nucleation of $\gamma_{\mathrm{R}}$ grain or a low-angle grain boundary. Precipitates and dislocations are exaggerated in size for visual clarity.

\section{ACKNOWLEDGMENTS}

Open access funding provided by Max Planck Society. The authors thank Siemens Industrial Turbomachinery $\mathrm{AB}$, Sweden for the provision of funding. P.K., B.G., and D.R. are grateful to the MPG for the funding of the Laplace project. J.J.M and M.S are grateful for the funding from the Swedish Energy Agency, Grant KME-702. Uwe Tezins and Andreas Sturm are acknowledged for their support on the APT and SEM/FIB facility at MPIE.

\section{OPEN ACCESS}

This article is distributed under the terms of the Creative Commons Attribution 4.0 International License (http://creativecommons.org/licenses/by/4.0/), which permits unrestricted use, distribution, and reproduction in any medium, provided you give appropriate credit to the original author(s) and the source, provide a link to the Creative Commons license, and indicate if changes were made.

\section{REFERENCES}

1. M. Segersäll, P. Kontis, S. Pedrazzini, P.A.J. Bagot, M.P. Moody, J.J. Moverare, and R.C. Reed: Acta Mater., 2015, vol. 95, pp. $456-67$.

2. J.J. Moverare, S. Johansson, and R.C. Reed: Acta Mater., 2009, vol. 57 , pp. 2266-76.

3. F. Sun, J. Zhang, and H. Harada: Acta Mater., 2014, vol. 67, pp. $45-57$.

4. M. Segersäll, D. Leidermark, and J.J. Moverare: Mater. Sci. Eng. $A$, 2014, vol. 623, pp. 68-77.

5. J. Kanesund, J.J. Moverare, and S. Johansson: Mater. Sci. Eng. A, 2011, vol. 528, pp. 4658-68.

6. J.J. Moverare and D. Gustafsson: Mater. Sci. Eng. A, 2011, vol. 528 , pp. $8660-70$.

7. W.D. Summers, E. Alabort, P. Kontis, F. Hofmann, and R.C. Reed: Mater. High Temp., 2016, vol. 33, pp. 338-45.

8. A. Pineau, D.L. McDowell, E.P. Busso, and S.D. Antolovich: Acta Mater., 2016, vol. 107, pp. 484-507. 
9. P. Kontis, E. Alabort, D. Barba, D.M. Collins, A.J. Wilkinson, and R.C. Reed: Acta Mater., 2017, vol. 124, pp. 489-500.

10. L. Mataveli Suave, J. Cormier, P. Villechaise, D. Bertheau, G. Benoit, F. Mauget, G. Cailletaud, and L. Marcin: in Superalloys 2016: 13th International Symposium, 2016, pp. 747-56.

11. P.A.S. Reed: Mater. Sci. Technol., 2009, vol. 25, pp. 258-70.

12. P. Kontis, D.M. Collins, S. Johansson, A.J. Wilkinson, J.J. Moverare, and R.C. Reed: in Superalloys 2016: 13th International Symposium, 2016, pp. 763-72.

13. A. Sato, J.J. Moverare, M. Hasselqvist, and R.C. Reed: Metall. Mater. Trans. A, 2012, vol. 43A, pp. 2302-15.

14. P. Kontis, H.A.M. Yusof, S. Pedrazzini, M. Danaie, K.L. Moore, P.A.J. Bagot, M.P. Moody, C.R.M. Grovenor, and R.C. Reed: Acta Mater., 2016, vol. 103, pp. 688-99.

15. S. Zaefferer and N.-N. Elhami: Acta Mater., 2014, vol. 75, pp. 20-50.

16. K. Thompson, D. Lawrence, D.J. Larson, J.D. Olson, T.F. Kelly, and B. Gorman: Ultramicroscopy, 2007, vol. 107, pp. 131-39.

17. T. Connolley, P.A.S. Reed, and M.J. Starink: Mater. Sci. Eng. A, 2003, vol. 340, pp. 139-54.

18. P. Kontis, D.M. Collins, A.J. Wilkinson, R.C. Reed, D. Raabe, and B. Gault: Scr. Mater., 2018, vol. 147, pp. 59-63.

19. X.Q. Liu, X.D. Han, Z. Zhang, L.F. Ji, and Y.J. Jiang: Acta Mater., 2007, vol. 55, pp. 2385-96.
20. S. Pedrazzini, D.J. Child, G. West, S.S. Doak, M.C. Hardy, M.P. Moody, and P.A.J. Bagot: Scr. Mater., 2016, vol. 113, pp. 51-54.

21. M. Kolbe, A. Dlouhy, and G. Eggeler: Mater. Sci. Eng. A, 1998, vol. 246, pp. 133-42.

22. M. Legros, G. Dehm, E. Arzt, and T.J. Balk: Science, 2008, vol. 319, pp. 1646-49.

23. R. Giraud, Z. Hervier, J. Cormier, G. Saint-Martin, F. Hamon, X. Milhet, and J. Mendez: Metall. Mater. Trans. A Phys. Metall. Mater. Sci., 2013, vol. 44, pp. 131-46.

24. D. Blavette, E. Cadel, A. Fraczkeiwicz, and A. Menand: Science, 1999, vol. 286, pp. 2317-19.

25. J. Wilde, A. Cerezo, and G.D.W. Smith: Scr. Mater., 2000, vol. 43, pp. 39-48.

26. G.D.W. Smith, D. Hudson, P.D. Styman, and C.A. Williams: Philos. Mag., 2013, vol. 93, pp. 3726-40.

27. A. Kwiatkowski da Silva, G. Leyson, M. Kuzmina, D. Ponge, M. Herbig, S. Sandlöbes, B. Gault, J. Neugebauer, and D. Raabe: Acta Mater., 2017, vol. 124, pp. 305-15.

28. S.K. Makineni, M. Lenz, P. Kontis, Z. Li, A. Kumar, P.J. Felfer, S. Neumeier, M. Herbig, E. Spiecker, D. Raabe, and B. Gault: JOM, 2018, pp. 1-8.

29. P. Kontis, Z. Li, D.M. Collins, J. Cormier, D. Raabe, and B. Gault: Scr. Mater., 2018, vol. 145, pp. 76-80. 